\title{
Learning about Professionalism within Practice- based Education: What are we looking for?
}

\author{
Rosemarie Mason* \\ University of East Anglia, Faculty of Medicine and Health Sciences, UK \\ Zoe Butterfint \\ University of East Anglia, Faculty of Medicine and Health Sciences, UK \\ Rachel Allen \\ University of East Anglia, Faculty of Medicine and Health Sciences, UK \\ Katherine Bygrave \\ University of East Anglia, Faculty of Medicine and Health Sciences, UK \\ Emily Gelder \\ University of East Anglia, Faculty of Medicine and Health Sciences, UK \\ Emma Pomroy \\ University of East Anglia, Faculty of Medicine and Health Sciences, UK
}

\begin{abstract}
Health and social care professions are being held to account concerning their professionalism in ways that would have been unprecedented in the recent past. Students of the School of Health Sciences (HSC) within the University of East Anglia (UEA) in the United Kingdom have professionalism taught and assessed in a number of ways and have overt opportunities to develop their professional performance during practice education. In order to augment this further, a UEA Professionalism Charter has been developed, which helps students to define, learn and apply professionalism in a particular way. Since professionalism is being scrutinised by a number of bodies it is important that there is agreement about its nature. Without an overt definition of professionalism from the Health and Care Professions Council (the regulatory body for occupational therapy, physiotherapy and speech and language therapy) this study set out to explore what could be learned about this body's perspective through analysis of its Fitness to Practice hearings. The outcome revealed that a definition could be identified and that this bears a close resemblance to that used within the UEA Professionalism Charter. The study therefore supports the continued use of the Charter.
\end{abstract}

Key Words: allied health professions; education; professionalism definition

\section{Introduction}

There was an age, prior to the 1960's, when health professions, world-wide, were held in high regard and were distinguished from other occupations by their expertise and altruism (Freidson 1994). Such was their reputation that there was little need for a definition. Subsequently, a more critical society has challenged this view, leading to the ideology of professionalism being attacked on a number of fronts and a lessening in the belief that its properties are essentially virtuous (Foster and Wilding 2000, Swick 2000, Bruhn 2001, Cruess and Cruess 2006).

Current Government policy in the United Kingdom is aimed at changing the way that health professionals deliver their services. There is now a market basis for health care, which is expected to be delivered with improved, client-focused care. There is an emphasis on more client power and better partnership and dialogue with healthcare providers. A First Class Service (Department of 
Health 1998) signified for the first time that healthcare professionals must be held accountable for the quality of their care. The concept of clinical governance was introduced, supported by structures such as National Service frameworks (NSF) and guidelines produced by the National Institute for Clinical Excellence (NICE). A raft of further legislation followed, more recently including High Quality Care for All (Department of Health 2008), The NHS Constitution (Department of Health 2013a), and the Health and Social Care Act (Department of Health 2012), which all emphasise increased accountability for the quality of service, more effective performance management and greater acknowledgement of the primacy of the client. This redefinition of the role of clients as consumers and of healthcare workers as providers of healthcare is significant. The intent is to bring equity into the relationship between the two, in contrast to traditional professional practice where the authoritative professional expert has primacy. Historically, this relationship, although patriarchal, has been a fiduciary one, yet, both the state and public have demonstrated dissatisfaction with professional behaviour lately and a decline in levels of trust (Swick 2000, Bruhn 2001, Cruess and Cruess 2006). It has become important for professionals to reaffirm their credentials (van Mook et al. 2009a).

Professions are held to account for their actions through their regulatory bodies: in the case of allied health professions, the Health and Care Professions Council (HCPC). The HCPC's responsibility includes publication of best practice guidelines, approval of qualifying courses, registration and monitoring of qualified professionals, and disciplinary processes for the 16 professions they regulate (Health and Care Professions Council 2012a). Despite the number of regulatory processes, there has been an inescapable change in the public perception of healthcare professions' capacity to deliver their contractual obligations. A number of reports, following recent scandals in the delivery of health and social care in the UK, call for a reawakening of professional behaviour among qualified staff and the recruitment, by universities, of applicants with the 'right' (that is, 'professional') values (Department of Health 2013b, Francis 2013, Keogh 2013, Clwyd and Hart 2013). Therefore, it is incumbent on Higher Education Institutions, responsible for the education of health and social care students, to have a clear idea of what it is they are looking for in the first place and what they are trying to teach within their professional education programmes.

Many authors have identified the importance of the educational curriculum in developing professionalism in doctors (Shapiro et al. 2006; O'Sullivan and Toohey, 2008; van Mook et al. 2009b, Passi 2010) and to some extent amongst allied health professionals (Kasar and Muscari 2000, Lindquist et al. 2006). Evidence from studies of doctors indicates that teaching professionalism is challenging for a number of reasons, not least because it is difficult to define and there have been substantive changes to the ways in which it is regarded in recent years (Cruess et al. 2004, O'Sullivan and Toohey 2008, van Mook et al. 2008, Van Mook et al. 2009c).

The problem in gaining a consensus definition of professionalism arises from differences in approach. Some writers are concerned with attributes, values and competencies, others with interpersonal relationships, and others with concepts such as the social responsibility of a profession, alongside an interest in self-identity (Passi et al. 2010). In Europe, health professionals are controlled by the state, so there are political agendas and economic considerations to take into account (Evetts 2003, Hodges et al. 2011). In 2002, a Physician's charter on professionalism was generated (Charter on Medical Professionalism 2002). This was a global exercise and seemed to reach an agreement on the responsibilities required of physicians, and yet the debates continue (van Mook et al. 2009c). Through a discourse analysis of key articles, Hodges et al. (2011) aimed to establish the constituent elements of appropriate professionalism in order that they might be assessed; the results being particularly relevant to education. The findings resulted in the identification of levels of professionalism, including an individual level, which takes into account attributes and characteristics, and an interpersonal level, in which behaviour, in a particular context and within a particular relationship is important.

However, behaviour does not always correlate to the possession of certain attitudes or values. It is possible to have an attitude that would be regarded as unhelpful (impatience, for example) and yet behave in a way that exhibits great patience. This need not be a problem. Cognitive dissonance theory suggests that in a culture where certain behaviours are not only expected but also governed, then eventually the associated attitudes and values will be internalised by individuals (van Mook et al. 2009c). 
Traditionally, it had been assumed that health students would absorb the elements of professionalism through socialisation, but it is now recognised that the concept must be explicitly taught (Cruess and Cruess 2006) and assessed (van Mook et al. 2009a, van Mook et al. 2009c). Studies within the medical profession suggest that learning about professionalism should take into account cognitive (factual) knowledge of the topic. Students must be informed about theoretical underpinnings and understand what professionalism is. They can then learn the behavioural components, which might include performance and skills acquisition (Hodges et al. 2011). In addition, specific character traits, attitudes and values need to be fostered (van Mook et al. 2009a, Wearn et al. 2010). Learning and assessment, therefore, require a combination of approaches that address each of these components. It is important to provide students with a definition of professionalism and then give opportunities for long-term experience and reflection on performance in different contexts and situations, particularly in practice, and to offer constructive feedback (van Mook et al. 2009a, Goldie 2013).

Students of the School of Health Sciences (HSC) within the University of East Anglia (UEA) have professionalism taught and assessed in a number of ways and have overt opportunities to develop their professional performance during practice education. A proportion of the programmes offered are devoted to practice-based education ( $30 \%$ for occupational therapy and physiotherapy). Whilst students are expected to behave professionally at all times, this is particularly the case during the clinical aspects of their education. In order to augment this further a UEA Professionalism Charter has been developed, the details of which have been published elsewhere (Mason et al. 2012a, Mason et al. 2012b). In the absence of an agreed definition of professionalism, we have chosen to frame the definition as an expression of the constituent parts; namely, professionalism encompasses twenty behaviours, skills and aspects of knowledge (collectively termed 'responsibilities'). The Charter was introduced to the 2011-12 cohorts of occupational therapy, physiotherapy, and speech and language therapy students.

Whilst not a contractual document between students and the UEA, the Professionalism Charter has the following aims:

- To define the construct of professionalism for HSC students,

- To provide a tangible framework around which professionalism can be structured,

- To enable students to map changes in their professional attitudes and behaviours,

- To highlight areas for development.

Students are expected to accumulate evidence of their growth in respect to each of the responsibilities within their continuing professional development portfolio. Evaluations to date have shown that the Charter is an effective mechanism through which to guide professional growth (Mason et al. 2014). However, given the difficulties in defining the concept, it is important to be assured that the principles being taught are consistent with those espoused by professional governing bodies. Variances in opinion need to be acknowledged, but ultimately it is the HCPC who judges professional practice. It is the HCPC definition of professionalism that matters to allied health students, but identifying this is not as easy as might be assumed.

At the same time that the Professionalism Charter was introduced, the HCPC commissioned its own research exploring professional practice. Whilst those of us who were working under the charter were confident that we had an appropriate definition of professionalism, we wanted to make sure that we were consistent with the most current position taken by the HCPC. The HCPC governs a range of professions including, occupational therapy, physiotherapy, and speech and language therapy. It publishes standards of proficiency, in addition to standards of conduct, performance and ethics. These documents provide guidance for safe and effective practice, with the overall aim of protecting the public (Health and Care Professions Council 2012b, Health and Care Professions Council 2012c, Health and Care Professions Council 2012d, Health and Care Professions Council 2013). There is however, no discrete definition of professionalism provided. The components are inferred through these documents, rather than made explicit. The first phase of the HCPC research was to explore registrants' perceptions of professionalism. The findings indicate that there is a value-based 
understanding of the concept, which could fall broadly into the individual and interpersonal levels of professionalism developed by Hodges et al. (2011). Adherence to codes, regulations and protocols, good clinical care and external perceptions were among the important items (Health Professions Council 2011). Beyond describing the concept as consisting of professional identity, professional attitudes and professional behaviour, a concise definition did not arise. It was noted though, that professionalism is demonstrated through behaviour. This is commonly regarded as a 'proxy measure', based on the assumption that outward performance reflects, at least to a degree, underlying dimensions of professionalism (Hodges et al. 2011). At times it can be straightforward to distinguish between good and poor professional behaviour. On other occasions there can be ambiguity, depending on the context. The use of humour, for example, can be appropriate or not, according to the situation (Health Professions Council 2011). This has relevance for practice based learning since this is where genuine experiences are provided from which students can learn the appropriate professional behaviour in a range of contexts. Judgements about professionalism in simulated situations (use of scenarios, for example) are notoriously open to disagreement. Experienced professionals can differ vastly about how they regard a simulated event (van Mook et al. 2009c). The inference is that observing behaviour in real situations is a more credible way of assessing professionalism.

It remains important to have some sort of baseline for students to work with so that they know what they are striving to achieve. Our task was to identify, if possible, how the HCPC judges professionalism. Much can be learned through the judgements that people make in a real situation. The HCPC is responsible for disciplinary processes, which are delivered through Fitness to Practice panels and hearings. The function of these panels is to make judgements about registrants' conduct in a wide array of situations. This provides a rich vein of data for scrutiny. The panels have the authority to impose a number of sanctions, which include mediation, caution, conditions of practice, suspension and striking off. By definition, Fitness to Practice hearings arise out of a registrant's fitness and safety to provide professional services being called into question (Health and Care Professions Council 2005).

It is reasonable, therefore, to suppose that the HCPC has a particular vision of professionalism against which to judge failures in fitness to practice. An investigation of the misdemeanours deemed severe enough to be dealt with through a panel and the level of sanction imposed could, by reverse logic, reveal the precise nature of professionalism as viewed by the HCPC. Once revealed, it would be straightforward to compare the HCPC vision of professionalism with that embodied in the UEA Professionalism Charter. To this end, a further evaluation of the UEA Professionalism Charter was undertaken as a student-led, supervised group dissertation project.

\section{Methods}

The project focused on exploring the HCPC definition of professionalism and the extent to which the professionalism charter harmonises with this. The following questions were addressed:

1. To what extent do failures in fitness to practice occur in the practice of occupational therapists, physiotherapists and speech and language therapists?

2. What are the failures in fitness to practice that occur in the practice of occupational therapists, physiotherapists and speech and language therapists?

3. What does the way in which these failures are adjudicated reveal about the Health and Care Professions Council's view of professionalism?

4. To what extent does the Health and Care Professions Council's view of professionalism ally with the UEA Professionalism Charter? 
The study focused on secondary analysis of published data from the HCPC website (http://www.hcpcuk.org). Details of the HCPC Fitness to Practice hearings, including personal details, hearing reports and outcomes, are openly available to the public. Once cases for analysis were identified from this database, as detailed below, they were assigned a reference number and no further personal details were recorded. In this way the data were treated sensitively and anonymously without losing information that was important to the study.

\section{Stage 1: To what extent do failures in fitness to practice occur in the practice of occupational therapists, physiotherapists and speech and language therapists?}

In the first part of the study the aim was to identify the extent of the problem. By examining the published HCPC Fitness to Practice hearings, we postulated that we could get an overview of the situation and note any similarities or differences between professions or outcomes.

Although the HCPC hearings hold data on the 16 professions under its regulation, this study considered data from speech and language therapists (SLT), occupational therapists (OT) and physiotherapists (PT) over a specific period of time. These are the professions for which the Professionalism Charter was generated. An initial examination of these cases revealed a total of 730 cases between October 2003 and October 2012. It was beyond the scope of this study to examine such a large number of cases in detail and therefore a subset was identified.

Selection criteria for the subset:

- Cases from SLT, OT and PT: these professions will have some commonality in their practice and are the professions at which the Professionalism Charter was originally aimed.

- Cases with the following outcomes: mediation, caution, conditions of practice, suspension, striking off. Cases where the outcome was unclear or still in progress were excluded.

- Cases taking place between 2008 to January 2012. This time frame was chosen because the HCPC guidelines on Standards of conduct, performance and ethics were revised in 2008 and it was important that our analysis was based on the decisions directed by the same set of standards.

In total, 170 cases were identified for the subset and included for examination at this stage. There were no cases of mediation in this data set. This is the lowest level of sanction and is considered to be more of a consensual process used where the fitness to practise impairment is of a minor and isolated nature, which is unlikely to recur, where the registrant fully understands the nature and effect of that impairment and has taken appropriate corrective action (Health and Care Professions Council 2005).

\section{Analysis and results}

Descriptive statistics were generated from examination of the identified 170 cases. The number of individuals in each of the three professions becoming the subject of Fitness to Practice hearings during this timeframe was small - less than $1 \%$ of total registrants in each case. Greater numbers of cases were seen among physiotherapists in this timeframe, followed by occupational therapy and then speech and language therapy. In all three professions a greater proportion of cases resulting in suspension or striking off orders was seen, but in most cases the proportion of each outcome was very similar. 


\section{Stage 2: What are the failures in fitness to practice that occur in the practice of occupational therapists, physiotherapists and speech and language therapists?}

In order to gain a more detailed understanding of the types of misdemeanours occurring in each of the three professions, and to explore the differences and similarities not only in the acts themselves, but also the sanctions imposed, it was necessary to select further a sub-set of the 170 cases identified in Stage 1.

To this end, it was decided to select four examples of each outcome from each profession based on their typicality in relation to the whole dataset. Typicality was established by reading the hearings and checking that the rationale for the choice of sanction was clearly stated and that reference was made to relevant guidelines. The final sub-set generated resulted in 47 cases for detailed analysis. Only 3 cases of caution for SLT were available within the original timeframe selected (Table 1).

Table 1: Sample Framework for Stage 2

\begin{tabular}{|l|l|l|l|}
\hline & SLT & OT & PT \\
\hline Caution & 3 & 4 & 4 \\
\hline COP & 4 & 4 & 4 \\
\hline Suspension & 4 & 4 & 4 \\
\hline Struck off & 4 & 4 & 4 \\
\hline
\end{tabular}

An enumerative level of thematic content analysis was chosen for the analysis of these cases. This is considered to be an appropriate way of looking at frequency of patterns (Grbich 2007). In this case we were interested in patterns of misdemeanour between sanctions and between professions. In preparation for the analytical process, a sample of four of the hearings was read independently by each of the researchers and themes were proposed. These were refined into codes with descriptive definitions to draft a codebook. From this we were able to ascertain that the types of misdemeanour fell into five themes: record keeping (with codes such as 'missing information'), behaviour (with codes such as 'lack of respect'), communication (with codes such as 'failure to communicate with patients and carers'), clinical competence (with codes such as 'unsafe practice') and caseload management (with codes such as 'lack of prioritisation'). All of the researchers met to compare, modify and agree the final codebook, which was then applied to the analysis of all 47 cases. Each case was examined for the frequency with which the coded acts occurred. Regular meetings ensured that there was good inter-coder agreement among all of the researchers. The results of this coding exercise were then examined.

\section{Analysis and results}

For each profession and each sanction the frequency of occurrence of each of the themes in the codebook was examined. Analysis of these cases reveals both similarities and differences between the three professions in terms of the misdemeanours noted and the resultant outcomes.

Cases resulting in a caution are seen to involve, for all three professions, issues coded as 'record keeping', particularly around missing or inaccurate information. In addition, for OT and PT there are noted difficulties around communication. Misdemeanours associated with record keeping are also noted, in increasing numbers, in the other three outcomes. In cases resulting in conditions of practice, 
issues appear more widespread and varied, again in relatively limited apparent number. However, there appears to be an increase in misdemeanours related to clinical competence and caseload management. In the more punitive outcomes there is a noticeable increase in the number of occurrences of the various misdemeanours and, although variation in the types of issues seen exists, the misdemeanours can be seen to group in specific areas. In the cases resulting in suspensions there is clear grouping of issues around record keeping, communication, clinical competence and caseload management, of an increasing number compared to those resulting in conditions of practice. In cases resulting in the clinician being struck off similar themes are noted, but with an increase in issues around behaviour, particularly sexually motivated behaviours. The predominance of issues linked to caseload management in this group seems to be reduced.

Broadly, the misdemeanours that occur can cover individuals' knowledge, skills and behaviours. Any of the misdemeanours could result in any of the sanctions, which would indicate that there is something qualitatively different about each event that leads to one sanction over another, beyond frequency of occurrence. Of particular interest is the tendency for the lower order of sanctions to be imposed for knowledge and skills deficits and that a significant deficit in behaviour is more likely to result in a striking off.

\section{Stage 3: What does the way in which these failures are adjudicated reveal about the Health and Care Professions Council's view of professionalism?}

This stage required a more interpretive examination of the hearings. A decision was made to use keyword in context analysis to investigate the failures in professionalism and the outcomes of the hearings. This is an aspect of thematic content analysis, used on text-based data, which allows specific words to be examined within the context in which they occur. Through looking at key words and those used either side of them, by interrogating why and how those words are used and by interpreting their meaning in a given context, a much greater depth of understanding can be achieved (Russell and Ryan 2010, Guest et al. 2012).

The following areas were subject to analysis on each of the 47 cases used in stage 2 :

a) The Allegation,

b) The Context of this Allegation,

c) The Act or Omission,

d) The sanction and the context of the decision.

\section{Findings}

The purposes of the HCPC hearings were clear, i.e. to determine the extent to which misconduct and or lack of competence had occurred and therefore the level to which fitness to practice was impaired. Reference to the HCPC Standards of Conduct, Performance and Ethics (Health and Care Professions Council 2012b) and profession-specific Standards of Proficiency was used across all professions and outcomes to justify the decisions made. The term 'misconduct' was used when the misdemeanour was wilful, intentional and behavioural; i.e. not from any lack of competence but a deliberate act or omission, betrayal of patient trust or a lack of professional integrity. The term 'lack of competence' was used in relation to insufficient knowledge and/or skills. The difference in usage of these terms appears to be the registrant's intent rather than the outcome of the misdemeanour.

The Indicative Sanctions Policy describes the capacity of registrants to move up or down the sanctions depending on their remedial action or continued unprofessionalism (Health and Care Professions Council 2005). In the cases examined, this movement between sanctions was evident. For example, a registrant who has had conditions of practice imposed could, at the next panel, move to a caution if things are going well, or to a suspension, if things have continued to go badly. A 
registrant who undertakes an act of misconduct in addition to lack of competence is more likely to be struck off. This is interesting since it suggests that the HCPC considers competence to be remediable and that the same cannot be assumed for misconduct.

\section{Trends within the sanctions}

\section{Caution}

A caution order is imposed upon a registrant for a fixed period of up to 5 years. The order appears on the register but does not restrict the registrant's practice (Health and Care Professions Council 2005). The allegations were largely attributed to lack of competence. The acts of incompetence could be minor, occurring over a short period of time, or were a single incident. On occasion the duration of incompetence was longer, in which case the context was considered. This might be that there were periods within the employment during which the registrant performed to an acceptable standard or that there was a lack of a clinical lead. Rarely, an allegation of misconduct appeared but this tended to be at a low level such as not prioritising record keeping. The registrants in these cases demonstrated insight and acceptance, and were undertaking remedial action such as taking a record keeping course. In addition, the cases examined in this category were considered a low risk to public safety and had a low risk of reoccurrence.

\section{Conditions of practice $(\mathrm{CoP})$}

A CoP order allows a registrant to continue practicing, but restricts their practice and requires them to undertake remedial action (Health and Care Professions Council 2005). The allegations in these cases were wide ranging. These might include a civil conviction which had no connection to the registrant's practice but had brought the profession into disrepute, or a series of failings in competence. It was common in these cases that the allegations were serious but the HCPC judged that the public would not be at risk by the registrant continuing to practice. Registrants in these cases demonstrated insight and the ability and a desire to address their deficiencies. The distinguishing point of difference between caution and CoP is that at the point of the hearing the registrant had not fully addressed his or her weaknesses.

\section{Suspension}

A suspension order prohibits a registrant from practising their profession and is used if registrants have no psychological or other issues preventing them from remedying their failings (Health and Care Professions Council 2005). Often the registrant's failings or deficiencies were serious and wide ranging such as failure to maintain the necessary degree of competence in assessment, treatment planning, clinical reasoning or documentation. There was little evidence that the registrants in these cases were addressing their shortcoming or engaging with the disciplinary process. Lack of insight was common and there was potential to compromise patient safety.

\section{Striking off}

Striking off is the most restrictive sanction available to the HCPC. It removes the registrant's name from the register permanently and prohibits her/him from practising (Health and Care Professions Council 2005). The allegations were found to largely involve misconduct as well as incompetence. It was common for previous disciplinary action to have been applied to the individual and the cases were considered to be extremely serious. Misconduct could include betrayal of patient trust, a lack of professional integrity, sexual misconduct, or breaches in Standards of Conduct, Performance and Ethics, where there was the potential for significant harm to vulnerable clients. Unique to this sanction was reference to registrant's lack of moral boundaries in relation to their conduct. The registrants tended to show a lack of insight, no remorse, and an inability to remedy failings. In some cases a single act warranted a striking off order such as sexual abuse occurring over a short span of time. In other cases failures were prolonged and repeated. Registrants were usually considered to be at a high risk of repeating the failures. 


\section{Stage 4: To what extent does the Health and Care Professions Council's view of professionalism ally with the UEA Professionalism Charter?}

Clearly, the HCPC disciplines incompetence and misconduct. From these acts or omissions it is fairly straightforward to work out what is required to constitute 'competence' and 'good conduct' and therefore, the required level of professionalism. A further, interpretive analysis was applied to the enumerative and key word in context analyses, in addition to the content of the HCPC Standards of Conduct, Performance and Ethics (Health and Care Professions Council 2012b). The aim was to formulate themes that reflected professional ideals. Sometimes this was obvious. For example, item 7 in the Standards of Conduct, Performance and Ethics states that 'You must communicate properly and effectively with service users and other practitioners'. This equates very well to a number of codes about communication in the Stage 2 analysis including, 'failure to communicate appropriately with patients and carers' and citations of communication failures in the stage 3 analysis. Thus, it can be concluded that 'effective communication' is valued by the HCPC as a professional ideal. At other times a little more thought was required. Level of insight was a predominant key word in the Fitness to Practice hearings. Insight also appeared in the Stage 2 codebook which, when considered in context, concerned self-awareness of one's performance. This best fit with item 4 in the Standards of Conduct, Performance and Ethics 'You must provide any important information about your competence and conduct'. Our conclusion was that self-awareness was the important factor.

\section{Findings}

The resultant themes were then compared and contrasted with the responsibilities within the UEA Professionalism Charter. The results, shown in Table 2, show good consistency about the way in which the HCPC and UEA Charter understands professionalism. 
Table 2: A comparison of the HCPC's and UEA Charter's understanding of professionalism

\begin{tabular}{|c|c|}
\hline HCPC Themes of Professionalism & $\begin{array}{l}\text { UEA Professionalism Charter } \\
\text { (C) University of East Anglia Norwich } 2012 . \\
\text { All rights reserved. }\end{array}$ \\
\hline Behave with honesty and integrity & Honesty and integrity \\
\hline $\begin{array}{l}\text { Hold high standards of personal conduct within } \\
\text { and outside of work }\end{array}$ & $\begin{array}{l}\text { Responsibility } \\
\text { Professional presentation }\end{array}$ \\
\hline Treat people with respect and dignity & $\begin{array}{l}\text { Altruism and respect for others } \\
\text { Empathy and compassion } \\
\text { Co-operation }\end{array}$ \\
\hline Act in the best interests of service users & Altruism and respect for others \\
\hline Have a good sense of self-awareness & Self-awareness \\
\hline Undertake reflective practice & Reflective practice \\
\hline $\begin{array}{l}\text { Ensure skills and knowledge are maintained and } \\
\text { developed }\end{array}$ & $\begin{array}{l}\text { Commitment to improve } \\
\text { Supervision } \\
\text { Reflective practice }\end{array}$ \\
\hline $\begin{array}{l}\text { Practise good organisation and time } \\
\text { management }\end{array}$ & $\begin{array}{l}\text { Organisation } \\
\text { Co-operation }\end{array}$ \\
\hline Practise effective verbal communication & $\begin{array}{l}\text { Effective verbal communication } \\
\text { Co-operation }\end{array}$ \\
\hline $\begin{array}{l}\text { Maintain accurate, detailed and clear records, } \\
\text { kept within approved timeframe }\end{array}$ & $\begin{array}{l}\text { Effective written communication } \\
\text { Co-operation }\end{array}$ \\
\hline Demonstrate sound clinical reasoning & Clinical reasoning \\
\hline Demonstrate clinical competence & $\begin{array}{l}\text { Initiative } \\
\text { Clinical reasoning } \\
\text { Competence } \\
\text { Judgement }\end{array}$ \\
\hline Demonstrate safe practice & $\begin{array}{l}\text { Clinical reasoning } \\
\text { Competence } \\
\text { Judgement }\end{array}$ \\
\hline $\begin{array}{l}\text { Act within the limits of knowledge, skills and } \\
\text { experience }\end{array}$ & $\begin{array}{l}\text { Responsibility } \\
\text { Self-awareness }\end{array}$ \\
\hline Respect confidentiality & Confidentiality \\
\hline Able to work as an autonomous practitioner & $\begin{array}{l}\text { Responsibility } \\
\text { Competence } \\
\text { Organisation } \\
\text { Trustworthiness and dependability } \\
\end{array}$ \\
\hline Maintain appropriate relationships & $\begin{array}{l}\text { Maintain appropriate relationships with service } \\
\text { users }\end{array}$ \\
\hline
\end{tabular}

Close scrutiny of the data in Table 2 reveals that the items can be stratified further into sets of knowledge/skills, attitudes and personality traits (Table 3). The HCPC and the UEA see professionalism in terms of the way that individuals act. More particularly, it is the way that an individual, with particular personality traits and attitudes, uses their attributes to apply their knowledge in practice. This harmonises with Hodges et al.'s (2011) way of thinking about professionalism at an 
individual level. There are also the relationships that these individuals have with others to consider, be that with clients or colleagues and the context in which behaviours take place. This is more in line with the view of professionalism as an interpersonal process (Hodges et al. (2011). This approach considers interpersonal relationships and the context in which they occur. It is reasonable to expect that a variety of approaches would be evident to a greater or lesser degree. This explains why similar behaviour can lead to differing disciplinary outcomes from the Fitness to Practice panels. It is interesting to note that having an inappropriate relationship with a client is likely to result in a striking off whereas being involved in a brawl and receiving a civil conviction (an expression of an inappropriate relationship with another person and the police) is more likely to result in conditions of practice. The HCPC apparently places greater emphasis on professionalism as it is constructed through relationships with clients (the individual and interpersonal approaches) than on the way it interacts with society (societal approach). The inference would be that it is more damaging to harm a client through poor professionalism than to harm the reputation of the profession, although this is still undesirable.

Table 3: Stratification of Professionalism Themes

\begin{tabular}{|l|l|l|}
\hline Knowledge and Skills & Attitudes & Personality \\
\hline Reflective practice & Altruism and respect for others & Honesty and integrity \\
\hline Organisation & Empathy and compassion & Responsibility \\
\hline $\begin{array}{l}\text { Effective verbal and written } \\
\text { communication }\end{array}$ & $\begin{array}{l}\text { Act in the best interests of } \\
\text { service users }\end{array}$ & $\begin{array}{l}\text { Hold high standards of personal } \\
\text { conduct within and outside of } \\
\text { work }\end{array}$ \\
\hline Clinical reasoning & & Self-awareness \\
\hline Competence & & Commitment to improve \\
\hline Judgement & & $\begin{array}{l}\text { Maintain appropriate } \\
\text { relationships with service users }\end{array}$ \\
\hline Confidentiality & \\
\hline $\begin{array}{l}\text { Able to work as an autonomous } \\
\text { practitioner }\end{array}$ & & \\
\hline
\end{tabular}

\section{Discussion}

The main purpose of trying to identify a specific definition is to inform teaching and learning about professionalism. It is important to pay attention to the different dimensions that have become apparent in this study and consider the implications for educators.

The analysis of the HCPC Disciplinary Hearings has shown that in cases of caution the misdemeanours tended to be limited in number and were often around record keeping and communication skills. The difference between caution and conditions of practice outcomes seemed to be the appearance of issues to do with clinical competence and/or caseload management. It appears that lapses in knowledge or skills are considered to be amenable to improvement and are disciplined as such. In cases of suspension and striking off, the number of instances of lapses in professionalism was seen to increase, along with an increase in more behavioural aspects of the misdemeanours. The level of insight shown and the potential for remediation was critical in deciding whether or not a registrant should still be allowed to practice. Behavioural problems were more stringently disciplined and considered to be much more intractable. This is interesting in the light of a study among doctors that was able to demonstrate an association between unprofessional behaviour in medical school and subsequent disciplinary action once qualified (Papadakis et al. 2005). This study was extended to identify three types of behaviour that were predictive of future unprofessional conduct: poor reliability and responsibility, lack of self-improvement and adaptability and poor initiative and motivation (Teherani et al. 2005). These tend to fall into the domain of personality traits and have some 
consistency with those noted in Table 3. This may suggest that psychometric testing of candidates prior to admission onto professional programmes is appropriate. There are numerous professionalism scales, primarily designed for doctors, but their reliability and validity are often called into question (Wearn et et al. 2010, Hodges et al. 2011) and there are few that are relevant to allied health professionals. This is an area for further investigation (Passi et al. 2010).

At the individual level of approach to professionalism, attention is paid to personality and the inherent traits that draw people to professional work (Hodges et al. 2011). The Charter specifies the kinds of personality-based behaviour to observe in students. This is helpful when students are undertaking practice education, where educators can make a point of looking for occasions where a student showed integrity, self-awareness or were reliable and took responsibility. Educators can provide feedback and reinforce positive behaviour. However, because behaviour is an approximation of what is going on underneath it is also necessary to assess knowledge, values and attitudes through other measures. This may include self-assessment, or discussion with a mentor who is prepared to question and probe such things as knowledge of a condition/intervention or the student's thoughts on being respectful or compassionate.

From the interpersonal stance, more attention is paid to relationships; between the student and practice educator, student and mentor, or student and faculty members. A more profound learning experience is possible by engaging students in a discourse where they have to explain their reasoning, or responses to events, actions and decision making in different and challenging situations with different people. This is a useful way to capture behaviours that require high level cognitive functioning such as clinical reasoning, judgement, safe practice, and autonomous working. Students not only have to demonstrate their clinical competence but also the ability to make judgements in situations where the condition and the intervention are identical but the relationship with the patient and with other health professionals are different and therefore different actions are required. This has implications on practice educators, who should be aware of their own behaviours that they are modelling to the student. They also need to be mindful of the values that they are portraying through their actions. Karnieli-Miller et al. 2010) noted many ways that positive role modelling can reinforce values-based behaviour, including being respectful to stigmatised populations, taking the time to listen to a client, communicating effectively with angry family members or taking pride in one's work. It is likely that different educators will vary in their response to different situations and it is important for students to see this and work out their own response to similar situations. The learning environment is also important. Creating a welcoming environment where people are acknowledged as students and are given safe and structured opportunities to demonstrate their abilities is an effective way of capitalising on the learning opportunities available (Karnieli-Miller et al. 2010). Thus, it is not only important for educators to provide experiences for students and observe their response, they must also analyse the interplay with the people and environment involved before making any assessments.

\section{Conclusion}

This study set out to identify the scope and nature of failures in fitness to practice of occupational therapists, physiotherapists and speech and language therapists. These data were used to reveal the Health and Care Professions Council's view of professionalism and extrapolate the clearest definition we can get about professionalism from the HCPC. Having established a close affinity between this and the UEA definition, the findings of the study support the continued use of the UEA Professionalism Charter. Although this study was from a western, UK perspective, the principles could be transferable to other cultures where value-based behaviour is important. The Charter provides a means to structure learning about professionalism by identifying an agreed understanding of the components. This allows observation and assessment of the responsibilities via varied and contextbased methods in line with common practice within medical education (Passi et al. 2010). 


\section{References}

Bruhn, J. (2001) 'Being Good and doing Good: The Culture of Professionalism in the Health Professions'. Health Care Manager 19 (4), 47-58

Charter on Medical Professionalism (2002) 'Medical professionalism in the new millennium: a physicians' charter'. The Lancet 359, 520-522

Clwyd, A. and Hart,T. (2013) A Review of the NHS Hospitals Complaints System. Putting Patients Back in the Picture [online] available from $<$ https://www.gov.uk/government/uploads/system/uploads/attachment data/file/255615/NHS complaints accessible.pdf $>$ [Date accessed 15/06/15 ]

Cruess, R.L. and Cruess, S.R. (2006) 'Teaching professionalism: general principles'. Medical Teacher28 (3), 205-208

Cruess, S.R., Johnston, S., and Cruess, R.L. (2004) "'Profession": A Working Definition for Medical Educators'. Teaching and Learning in Medicine 16 (1), 74-76 Department of Health (1998) A First class Service: Quality in the new NHS[online] available from <http://webarchive.nationalarchives.gov.uk/+/www.dh.gov.uk/en/publicationsandstatistics/publ ications/publicationspolicyandguidance/dh 4006902> [Date accessed 15/06/15 ]

Department of Health (2008) High Quality Care For All [online] available from <https://www.gov.uk/government/publications/high-quality-care-for-allnhs-next-stage-review-final-report> [Date accessed 15/06/15 ]

Department of Health (2012) Health and Social Care Act [online available from <https://www.gov.uk/government/publications/health-and-social-care-act-2012-fact-sheets> [Date accessed 15/06/15 ]

Department of Health (2013a) The NHS Constitution for England [online] available from $<$ https://www.gov.uk/government/publications/the-nhs-constitution-for-england > [Date accessed 15/06/15 ]

Department of Health. (2013b) Transforming care: A national response to Winterbourne View Hospital [online] available from<https://www.gov.uk/government/publications/winterbourne-viewhospital-department-of-health-review-and-response> [Date accessed 15/06/15 ]

Evetts,J. (2003) 'The Sociological Analysis of Professionalism: Occupational Change in the Modern World'. International Sociology 18 (2), 395-414

Foster, P. A. and Wilding, P. (2000) 'Whither Welfare Professionalism?'. Social Policy and Administration 34 (2), 143-159

Francis R. (2013). Report of the Mid Staffordshire NHS Foundation trust Public Inquiry. London: www.official-documents.gov.uk [Date accessed 15/06/15]

Freidson, E. (1994). Professionalism Re-born. Theory, Prophecy and Policy. Cambridge: Polity Press.

Goldie, J. (2013) 'Assessment of Professionalism: A consolidation of current thinking'. Medical Teacher online] 35, e952-e956. Available from http://eprints.gla.ac.uk/69103/ [Date accessed 15/06/15]

Gordon, J. (2003) 'Fostering students' personal and professional development in medicine: a new framework'. Medical Education 37, 341-349

Grbich, C. (2007) Qualitative data analysis: an introduction. London: SAGE 
Guest, G., MacQueen, K.M., and Namey, E.E. (2012) Applied Thematis Analysis. London: Sage

Health and Care Professions Council (2012a) Why Your HCPC Registration Matters $<$ [online] available from http://www.hcpc-uk.org/publications/> [Date accessed 15/06/15 ]

Health and Care Professions Council (2012b) Standards of Conduct, Performance and Ethics [online] available from <http://www.hcpc-uk.org/publications/> [Date accessed15/05/15 ]

Health and Care Professions Council (2012c) Standards of Proficiency. Physiotherapists [online] available from <http://www.hcpc-uk.org/publications/> [Date accessed 15/06/15 ]

Health and Care Professions Council (2012d) Standards of Proficiency. Speech and Language Therapists [online] available from <http://www.hcpc-uk.org/publications/> [Date accessed 15/06/15]

Health and Care Professions Council (2013) Standards of Proficiency. Occupational therapists [online] available from <http://www.hcpc-uk.org/publications/> [Date accessed 15/06/15 ]

Health Professions Council (2011) Professionalism in healthcare professionals [online] available from <http://www.hpc-uk.org/publications/index.asp?id=511\#publicationSearchResults> [Date accessed 15/06/15 ]

Health and Care Professions Council (2005) Indicative Sanctions Policy [online] available from <http://www.hcpc-uk.org/publications/> [Date accessed 15/06/15 ]

Hodges, B.D., Ginsburgh, S., Cruess, R., Cruess, S., Delport, R., and Hafferty, F. (2011) 'Assessment of professionalism: Recommendations from the Ottawa 2010 Conference'. Medical Teacher 33, 354-363

Karnieli-Miller, O, Vu, T.R., Holtman, M.C., Clyman, S.G., and Inui, T.S. (2010) ,Medical Students' Professionalism Narratives: A Window on the Informal and Hidden Curriculum'. Academic Medicine 85 (1), 124-133

Kasar, J. and Muscari, M.E. (2000) 'A conceptual model for the development of professional behaviours in occupational therapists'. Canadian Journal of Occupational Therapy 67 (1), 4350

Keogh, B. (2013) Review into the Quality of care and Treatment Provided by 14 Hospital Trusts in England [Online] available from <http://www.nhs.uk/NHSEngland/bruce-keoghreview/Documents/outcomes/keogh-review-final-report.pdf> [Date accessed 15/06/15 ]

Lindquist, I., Engardt, M., Garnham, L., Poland, F., and Richardson, B. (2006) 'Physiotherapy students' professional identity on the edge of working life'. Medical Teacher 28 (3), 270-276

Mason, R. V. J., Vitkovitch, J., Lambert, R. and Jepson, J. (2014) 'Knowing about and performing professionalism: Developing professionalism in interprofessional healthcare education'. International Journal of Practice-Based Learning in Health and Social care 2, (1), 96-107 DOI: 10.11120/pblh.2013.00027 See http://journals.heacademy.ac.uk/doi/abs/10.11120/pblh.2013.00027 [Date accessed 15/05/15]

Mason R, Vitkovitch J, Jepson J, Lambert R. (2012a). Having the Conversation. RCSLT Bulletin, September 18-19

Mason, R., Jepson, J., Vitkovitch, J., and Lambert, R. (2012b) 'Instilling professionalism in education'. OT news, October 30-31

O'Sullivan, A.J. and Toohey, S.M. (2008) 'Assessment of professionalism in undergraduate medical students'. Medical Teacher 30 (3), 280-286 
Passi, V., Doug, M., Peile, E., Thistlethwaite, J., and Johnson, N. (2010) 'Developing medical professionalism in future doctors: a systematic review'. International Journal of Medical Education (1), 19-29

Papadakis, M. A., Teherani, A., Banach, M.A., Knettler, T.R., Ratner, S.L., and Stern, D.T. (2005) 'Disciplinary action by medical boards and prior behavior in medical school'. New England Journal of Medicine 353, 673-2682

Russell, R. H. and Ryan, G. W. (2010) Analysing Qualitative Data: Systematic Approaches. CA, U.S.A: Sage Publications, Inc.

Shapiro, J., Rucker, L., and Robitshek, D. (2006) 'Teaching the art of doctoring: an innovative medical student elective'. Medical Teacher 28 (1), 30-35

Swick, H.M. (2000) 'Toward a Normative Definition of Medical Professionalism'. Academic Medicine 75 (6), 612-616

Teherani, A., Hodgson, C.S., Banach, M., and Papadakis, M.A. (2005) 'Domains of Unprofessional Behavior During Medical School Associated with future Disciplinary Action by a State medical Board'. Academic Medicine 80 (10), 17-20

van Mook W.N.K.A., deGrave W. S., Wass V., O'Sullivan, H., Zwaveling, J. H., Schuwirth, L. W., vandeVleuten, C. P. M. (2008) 'Professionalism: Evolution of the concept'. European Journal of Internal Medicine [online] 20 (4), e81-e84. available from<< http://www.sciencedirect.com/science/article/pii/S0953620508002999> [Date accessed $15 / 06 / 15$ ]

van Mook W.N.K.A., van Luijk S.J., O'Sullivan H., Wass V., Schuwirth L.W., van der Vleuten P.M. (2009a). General considerations regarding assessment of professional behavior. European Journal of Internal Medicine, www.elsevier.com/locate/ejim 20: e90-e95 [Date accessed $15 / 06 / 15$ ]

van Mook WNKA, de Grave W.S, van Luijk SJ, O'Sullivan H, Wass V, Schuwirth LW, (2009b). Training and learning professionalism in the medical school curriculum: Current considerations. European Journal of Internal Medicine, 20: e96-100 www.elsevier.com/locate/ejim [Date accessed 15/06/15 ]

van Mook WNKA, Scheltus J, O'Sullivan H, Wass D, Zwaveling JH, Schuwirth LW,() (2009c). The concepts of professionalism and professional behaviour: Conflicts in both definition and learning outcomes. . European Journal of Internal Medicine, 20 e85-e89 www.elsevier.com/locate/ejim [Date accessed 15/06/15 ]

Wearn, A., Wilson, H., Hawken, S. J., Child, S., and Mitchell, C. J. (2010) 'In Search of Professionalism: Implications for Medical Education'. Journal of the New Sealand Medical Association 123 (1314),123-32 